\title{
PREVALENCE OF MRSA AMONG CLINICAL ISOLATES AND THEIR ANTIBIOGRAM IN A TERTIARY CARE HOSPITAL
}

\author{
Vijaya Durga Suryadevara1 ${ }^{1}$ Anuradha Basavaraju², Keerthi Vasireddy ${ }^{3}$
}

${ }^{1}$ Associate Professor, Department of Microbiology, Mamata Medical College, Khammam, Telangana.

2 Professor and HOD, Department of Microbiology, Mamata Medical College, Khammam, Telangana.

3Postgraduate Student, Department of Microbiology, Mamata Medical College, Khammam, Telangana.

\begin{tabular}{l}
\hline ABSTRACT \\
BACKGROUND \\
Methicillin resistance staphylococcus aureus (MRSA) is one of the most serious contemporary challenges to the treatment of \\
hospital acquired infections, because of its global spread prevalence. We aimed to screen the prevalence and assess the antibiotic \\
susceptibility pattern of MRSA from clinical specimens in a tertiary care hospital.
\end{tabular}

\section{MATERIALS AND METHODS}

A total of 210 Staphylococcal strains were collected from different clinical samples and 165 isolates were identified as Staphylococcus aureus and subjected to MRSA screening using standard methods. Subsequently, the antibiotic sensitivity test was performed for the confirmed MRSA and MSSA isolates.

\section{RESULTS}

Our study showed $32.12 \%$ of S. aureus infections were MRSA. All clinical MRSA strains (100\%) were resistant to penicillin, $84.9 \%$ to ciprofloxacin, $79.2 \%$ to ampicillin and $62.2 \%$ towards gentamicin and erythromycin, $60 \%$ to cefotaxime, $45.28 \%$ to amikacin and $28.3 \%$ to linezolid. However, all strains of clinical subjects were sensitive to vancomycin.

\section{CONCLUSION}

Knowledge of prevalence and antibiotic sensitivity pattern of MRSA will help the treating clinicians for formulation of definite antibiotic policy and restricts the use of higher antibiotics.

\section{KEYWORDS}

MRSA, Prevalence, Staphylococcus Aureus, Antibiotics.

HOW TO CITE THIS ARTICLE: Suryadevara VD, Basavaraju A, Vasireddy K. Prevalence of MRSA among clinical isolates and their antibiogram in a tertiary care hospital. J. Evolution Med. Dent. Sci. 2017;6(21):1667-1669, DOI: 10.14260/Jemds/2017/367

\section{BACKGROUND}

Staphylococcus aureus is one of the most common cause of nosocomial as well as community acquired infection. S. aureus mainly cause various infections acquired from different sources like patients, hospital staff mainly through their hands and also from their normal flora. ${ }^{1} \mathrm{~S}$. aureus produces various infections ranging from minor skin infection to life-threatening infections. ${ }^{2}$ Methicillin resistant staphylococcus aureus (MRSA) strains has emerged as one of the commonest nosocomial pathogens. ${ }^{3}$ Infection with MRSA strains is likely to be more severe, requires longer hospitalisation and is associated with considerable increase in morbidity, mortality and health care costs. 4 MRSA colonises healthy individuals and cause severe infection in hospitalised patients and is serious therapeutic challenge. ${ }^{5}$

The spread of MRSA may indicate that preventive strategies recommended are either improperly implemented or inadequate. The incidence of MRSA in India ranges from 30 - 70\%.6 MRSA is a major health care associated (HA-MRSA) as

Financial or Other, Competing Interest: None.

Submission 03-02-2017, Peer Review 27-02-2017,

Acceptance 06-03-2017, Published 13-03-2017.

Corresponding Author:

Dr. Vijaya Durga Suryadevara,

Department of Microbiology,

Mamata Medical College,

Khammam-507002, Telangana.

E-mail: durgasv11@yahoo.com

DOI: $10.14260 /$ jemds $/ 2017 / 367$ well as a community associated (CA-MRSA) infection causing wide range of diseases.7 MRSA infection is a serious concern, because of its resistance to commonly used antibiotics. Many of the MRSA isolates are becoming multidrug resistant and are showing susceptibility only to glycopeptides such as vancomycin. At present, they are showing low level resistance even to vancomycin. ${ }^{2}$ Control of MRSA isolates in hospitals and communities is a major challenge as the resistance phenotype varies according to the environmental conditions. 6 Therefore early detection, knowledge of local prevalence and formulation of effective antibiotic policy in a tertiary care hospital is of paramount importance. The present study has been carried out to know the prevalence and antibiogram of staphylococcus aureus with special reference to MRSA in a tertiary care hospital.

\section{MATERIALS AND METHODS}

Our study included 210 non-duplicate staphylococcal isolates from various clinical samples of pus, sputum, blood, urine and body fluids from patients of both admitted cases (IPD) and Outpatient Departments (OPD) from February 2013 to December 2015. The specimens were cultured on blood agar and MacConkey agar plates and incubated aerobically at $37^{\circ} \mathrm{C}$ for 48 hours. Identification of the isolates was carried out by standard laboratory operating procedures (Gram staining, catalase test, slide and tube Coagulase test and growth on Mannitol salt agar). ${ }^{8}$ Antibiotic sensitivity testing of all the strains was performed by modified Kirby-Bauer disc diffusion method as per CLSI guidelines for the following antibiotics penicillin (10 units), Gentamycin (10 $\mu \mathrm{g})$, Erythromycin (15 
$\mu \mathrm{g})$, ciprofloxacin (5 $\mu \mathrm{g})$, Linezolid (30 $\mu \mathrm{g})$, Amikacin (30 $\mu \mathrm{g})$ Ampicillin (10) cotrimoxazole (35), Cefotaxime (30 $\mu \mathrm{g})$, Vancomycin $(30 \mu \mathrm{g})$ and cefoxitin $(30 \mu \mathrm{g})$ obtained from $\mathrm{Hi}-$ Media, Mumbai.

Antibiogram was done on Muller-Hinton agar, and were interpreted after $24 \mathrm{hrs}$. of aerobic incubation at $37^{\circ} \mathrm{C}$. Testing for Methicillin resistance was performed using cefoxitin $(30 \mu \mathrm{g})$ disc diffusion method as per CLSI recommendations. The zone diameters were measured around each antibiotic disc and interpreted as per CLSI guidelines using S. aureus ATCC 25923 as a standard control strain. The isolates were considered as Methicillin resistant if the zone of inhibition was $\leq 21 \mathrm{~mm}$. The data was recorded and statistical analysis was done using (SPSS 17) to calculate $\mathrm{P}$ - value.

\section{RESULTS}

Out of 210 staphylococcal isolates, 165 (78.57\%) were staphylococcus aureus and $45(21.43 \%)$ were coagulase negative staphylococci. Among the 165 staphylococcus aureus isolates, 53 (32.12\%) were MRSA. Highest numbers of isolates were from pus and wound swab and least in blood and body fluids. Distribution of Methicillin Sensitive Staphylococcus aureus (MSSA) and MRSA among the clinical samples is given in Table 1 and isolates from Outpatient Departments (OPD) and Inpatient Departments (IPD) in Table 2.

\begin{tabular}{|c|c|c|c|}
\hline $\begin{array}{c}\text { Clinical } \\
\text { Specimen }\end{array}$ & $\begin{array}{c}\text { No. of Staph. } \\
\text { aureus Isolates }\end{array}$ & $\begin{array}{c}\text { MRSA } \\
\text { (\%) }\end{array}$ & $\begin{array}{c}\text { MSSA } \\
\text { (\%) }\end{array}$ \\
\hline $\begin{array}{c}\text { Pus and } \\
\text { wound swab }\end{array}$ & 108 & $41(37.9)$ & $67(62.10)$ \\
\hline Urine & 42 & $12(28.57)$ & $30(71.43)$ \\
\hline Sputum & 6 & - & $6(100 \%)$ \\
\hline Blood & 3 & - & $3(100 \%)$ \\
\hline CSF & 3 & - & $3(100 \%)$ \\
\hline Synovial fluid & 3 & - & $3(100 \%)$ \\
\hline Total & $\mathbf{1 6 5}(\mathbf{1 0 0 )}$ & $\mathbf{5 3}(\mathbf{3 2 . 1 2} \%)$ & $\mathbf{1 1 2}(\mathbf{6 7 . 8 8})$ \\
\hline Table 1. Distribution of MRSA and MSSA among Clinical \\
Samples \\
\hline
\end{tabular}

\begin{tabular}{|c|c|c|c|c|}
\hline $\begin{array}{c}\text { Clinical } \\
\text { Specimen }\end{array}$ & \multicolumn{2}{|c|}{ MRSA (53) } & \multicolumn{2}{c|}{ MSSA (112) } \\
\hline & IPD & OPD & IPD & OPD \\
\hline Pus (108) & 31 & 10 & 52 & 15 \\
\hline Urine (42) & 6 & 6 & 12 & 18 \\
\hline Sputum (6) & - & - & 6 & - \\
\hline Blood & - & - & 3 & - \\
\hline CSF & - & - & 3 & - \\
\hline $\begin{array}{c}\text { Synovial Fluid } \\
\text { (3) }\end{array}$ & - & - & 3 & - \\
\hline Total (168) & 37 & 16 & 79 & 33 \\
\hline $\begin{array}{c}\text { Table 2. Distribution of MRSA Isolates from OPD and IPD } \\
\text { among the Clinical Samples }\end{array}$
\end{tabular}

Out of 53, overall percentage of MRSA from OPD and IPD is $30.18 \%$ and $69.82 \%$ respectively. The distribution of $\mathrm{S}$. aureus and MRSA among male and female is given in Table 3 and resistance pattern of MRSA and MSSA to various antibiotics in Table 4.

\begin{tabular}{|c|c|c|}
\hline Gender & S. aureus & MRSA \\
\hline Female & 108 & 32 \\
\hline Male & 102 & 21 \\
\hline Total & $\mathbf{2 1 0}$ & $\mathbf{5 3}$ \\
\hline \multicolumn{2}{|c|}{ Table 3. Distribution of S. aureus and MRSA } \\
among Male and Female \\
\hline
\end{tabular}

\begin{tabular}{|c|c|c|c|c|}
\hline Antibiotic & \multicolumn{2}{|c|}{ MRSA (n = 53) } & \multicolumn{2}{c|}{ MSSA (n = 112) } \\
\hline & No. & $\%$ & No. & $\%$ \\
\hline Penicillin & 53 & $100 \%$ & 84 & $75 \%$ \\
\hline Ampicillin & 42 & $79.2 \%$ & 47 & $41.9 \%$ \\
\hline Gentamycin & 33 & $62.2 \%$ & 28 & $25 \%$ \\
\hline Erythromycin & 33 & $62.2 \%$ & 42 & $37.5 \%$ \\
\hline Ciprofloxacin & 45 & $84.9 \%$ & 47 & $41.9 \%$ \\
\hline Cefotaxime & 32 & $60 \%$ & 48 & $42.8 \%$ \\
\hline Amikacin & 24 & $45.28 \%$ & 45 & $40.17 \%$ \\
\hline Cotrimoxazole & 17 & $32.07 \%$ & 24 & $21.42 \%$ \\
\hline Vancomycin & - & - & - & - \\
\hline Cefoxitin & 53 & $100 \%$ & - & - \\
\hline Linezolid & 15 & $28.3 \%$ & - & - \\
\hline Table 4. Resistance Pattern of MRSA and MSSA to \\
\multicolumn{5}{|c|}{ Antibiotics } \\
\hline
\end{tabular}

\section{DISCUSSION}

The significance of MRSA has been recognised relatively late in India, and it emerged as a problem in last decades of $20^{\text {th }}$ century. Strains of MRSA are also showing resistance to several other antibiotics. ${ }^{9}$ The major reservoirs of MRSA in hospital are infected or carrier patients and transient carriage of them by healthcare workers. ${ }^{10}$

In this study, the prevalence of MRSA was $32.12 \%$. The prevalence of MRSA varies from $0.4 \%$ to $48.4 \%$ among different countries. ${ }^{11}$ In India MRSA prevalence varies in different areas, which might be because of several factors like efficacy of infection control policies, healthcare facilities and antibiotic usage that vary from one hospital to other. ${ }^{12}$

Maximum samples of MRSA were isolated from pus followed by urine. In comparison to inpatient and outpatient departments, MRSA were $69.82 \%$ (37) and $30.18 \%$ (16) respectively.

The resistance pattern of IPD - MRSA were higher when compared to those of OPD - MRSA, which may be due to chronic carrier stage among healthcare workers, greater resistance of the strain, prolonged hospital stay, emergency surgery, admission in ICU or Burns Unit and receipt of antibiotics before coming to the hospital. ${ }^{13}$

There is no significant difference in infection of males and females with staphylococcus aureus, whereas resistant types (MRSA) were slightly higher in females. This may be due to different factors such as microbial community in patient bodies, method and distribution of specimen collection during the period of the study. ${ }^{14}$

MRSA has become one of the established hospital acquired pathogen and its epidemiology is gradually changing and the association of multidrug resistance with MRSA has added to the problem. $\beta$-Lacto antibiotics were not found to be effective against MRSA.

Very high resistance to quinolones (Ciprofloxacin 84.9\%) was also found, which correlates with other studies. 15

MRSA strains were to be more resistant to other antibiotics than MSSA strains. Significant difference $(\mathrm{p}<$ 0.005) was observed in case of penicillin, erythromycin, ciprofloxacin, Ampicillin and Gentamycin. However, the difference observed in case of Amikacin and Cotrimoxazole was insignificant $(P>0.05)$. Our study shows a marked difference between sensitivity pattern of MRSA and MSSA, which also correlates with Vidhani S et al,16 Majumder D et $\mathrm{al}^{17}$ and Shilpa Arora et al. ${ }^{12}$ 
Linezolid has good activity against staphylococci including MRSA. Thus, it is a promising therapeutic option. ${ }^{18}$ In the present study all the isolates (MRSA and MSSA) were sensitive to vancomycin, which is in accordance with other studies2,6,19; however, regular monitoring of vancomycin sensitivity and routine testing of other new glycopeptides should be carried out to prevent the emergence of resistance.

\section{CONCLUSION}

Vancomycin remains the first choice of treatment for MRSA. To preserve its value, use of vancomycin should be limited for the treatment of resistant and life-threatening infections. Regular surveillance of hospital associated infections including MRSA and their local resistance profiles may be helpful for formulation of definite antibiotic policy and for effective infection control practices.

\section{REFERENCES}

[1] Singh NKR, Kalia K, Patel JS. A survey on prevalence rate \& antibiotic susceptibility test (AST) pattern of Methicillin Resistant Staphylococcus aureus (MRSA) isolate from various types of clinical specimen \& healthy hospital staff as carriers, Anand district. JPBMS 2012;16(17).

[2] Tiwari HK, Das AK, Sapkota D, et al. Methicillin resistant staphylococcus aureus: prevalence and antibiogram in a tertiary care hospital in western Nepal. J Infect Dev Ctries 2009;3(9):681-4.

[3] Kumar PD, Nigudgi A, Gangane R. Methicillin resistant staphylococcus aureus - prevalence and antibiogram in a tertiary care hospital. World Journal of Pharmacy \& Pharmaceutical Sciences 2013;2(5):3199-206.

[4] Shurland S, Zhan M, Bradham DD, et al. Comparison of mortality risk associated with bacteremia due to methicillin-resistant and methicillin-susceptible staphylococcus aureus. Infect Control Hosp Epidemiol 2007;28(3):273-9.

[5] Muralidharan S. Special article on methicillin resistant staphylococcus aureus. J Acad Clin Microbiol 2009;11:15-6.

[6] Rajaduraipandi K, Mani KR, Panneerselvam K, et al. Prevalence and antimicrobial susceptibility pattern of methicillin resistant staphylococcus aureus: a multicentre study. Indian J Med Microbiol 2006;24(1):34-8.

[7] Jana H, Roy T, Dey R, et al. Prevalence and antimicrobial susceptibility pattern of different clinical isolates of HA-MRSA and CA-MRSA in a tertiary care rural hospital, Bankura, West Bengal, India. Sch J App Med Sci 2015;3(2F):944-8.
[8] Collee JG, Miles RS, Watt B. Test for the identification of bacteria. In: Mackie, McCartney. eds. Practical medical microbiology. 14th edn. New York: Churchill Livingstone 1996:131-45.

[9] Barid D. Staphylococcus: cluster-forming Grampositive cocci. Chapter 11. In: Mackie, McCartney practical medical microbiology. Collee JG, Fraser AG, Marmion BP, et al. eds. 14th edn. New York: Churchill Livingstone 1996. p. 247.

[10] McDonald M. The epidemiology of methicillin resistant staphylococcus aureus: surgical relevance 20 years on. Aust N Z J Surg 1997;67(10):682-5.

[11] Sader HS, Farrell DJ, Jones RN. Antimicrobial susceptibility of Gram-positive cocci isolated from skin and skin-structure infections in European medical centres. Int J Antimicrob Agents 2010;36(1):28-32.

[12] Arora S, Devi P, Arora U, et al. Prevalence of methicillin-resistant Staphylococcus aureus (MRSA) in a tertiary care hospital in northern India. Journal of Laboratory Physicians 2010;2(2):78-81.

[13] Srinivasan S, Sheela D, Shashikala R, et al. Risk factors and associated problems in the management of infections with methcillin resistant Staphylococcus aureus. IJMM 2006;24(3):82-5.

[14] Al-Zoubi MS, Al-Tayyar IA, Hussein E, et al. Antimicrobial susceptibility pattern of Staphylococcus aureus isolated from clinical specimens in northern area of Jordan. Iran J Microbiol 2015;7(5):265-72.

[15] Shankar UC, Harish BN, Kumar UPM, et al. Prevalence of methicillin resistant staphylococcus aureus in JIPMER hospital. Indian J Med Microbioll 1997;15:1378.

[16] Vidhani S, Mehndiratta PL, Mathur MD. Study of methicillin resistant Staphylococcus aureus isolates from high risk patients. Indian J Med Microbiol 2001;19(2):13-6.

[17] Majumder D, Bordoloi JS, Phukan AC, et al. Antimicrobial susceptibility pattern among methicillin resistant staphylococcus isolates in Assam. Indian J Med Microbiol 2001;19(3):138-40.

[18] Kulkarni S, Khare A, CharanKaur D. Prevalence of methicillin resistant staphylococcus aureus - a study in a tertiary care rural hospital. Indian Journal of Basic and Applied Medical Research 2014:3(3):414-21.

[19] Anupurba S, Sen MR, Nath G, et al. Prevalence of methicillin resistant staphylococcus aureus in a tertiary referral hospital in eastern Uttar Pradesh. Indian J Med Microbiol 2003;21(1):49-51. 